\title{
ASPHER Statement: Déjà vu? Planning for the Covid-19 Third Wave and Planning for the Winter 2021-22
}

\begin{abstract}
Vasco Ricoca Peixoto ${ }^{1,2}$, John Reid ${ }^{3}$, Henrique Lopes ${ }^{4}$, Vladimir Prikazsky ${ }^{5}$, Ines Siepmann ${ }^{6}$, Jose M. Martin-Moreno ${ }^{7}$ and John Middleton ${ }^{8 *}$ on behalf of ASPHER COVID task force

${ }^{1}$ NOVA National School of Public Health, Public Health Research Centre, Universidade NOVA de Lisboa, Lisbon, Portugal, ${ }^{2}$ Comprehensive Health Research Centre, Universidade Nova de Lisboa, Lisbon, Portugal, ${ }^{3}$ Department of Public Health and Wellbeing, Chester University, Chester, United Kingdom, ${ }^{4}$ Unit of Public Health, Healthcare Sciences Institute, Universidade Católica, Lisbon, Portugal, ${ }^{5}$ Independent Public Health Expert, Prague, Czechia, ${ }^{6}$ ASPHER Young Professional, Brussels, Belgium, ${ }^{7}$ Medical School and INCLIVA-Clinical Hospital, University of Valencia, Valencia, Spain, ${ }^{8}$ Department of Public Health, Wolverhampton University, Wolverhampton, United Kingdom
\end{abstract}

Keywords: Public Health, COVID-19, pandemic, third wave, winter planning

\section{INTRODUCTION}

A "third wave" of the pandemic has arrived in Europe. The Delta variant of SARS-COV2, is now widespread. Relaxations in pandemic control measures have been accompanied by surges in cases [1]. Concerns we reported ahead of the second wave are still relevant today, conveying a sense of deja-vu on last year's concerns and recommendations [2]. Scientific knowledge is incomplete and we cannot yet appreciate the potential impact of SARS-COV2 on human and animal health, and on social and environmental conditions. How countries collectively respond will determine which road the pandemic takes, and how well we can control the pandemic in Europe and globally [3].

\section{ASPHER BELIEVES COUNTRIES MUST}

\section{OPEN ACCESS}

Approved by:

Nino Kuenzli,

Swiss Tropical and Public Health Institute (Swiss TPH), Switzerland

*Correspondence: John Middleton john.middleton@aspher.org

Received: 22 July 2021 Accepted: 04 August 2021 Published: 23 August 2021

Citation:

Peixoto VR, Reid J, Lopes $H$, Prikazsky V, Siepmann I, Martin-Moreno JM and Middleton $J$ (2021) ASPHER Statement: Déjà vu? Planning for the Covid-19 Third Wave and Planning for the Winter 2021-22. Int J Public Health 66:1604361. doi: 10.3389/ijph.2021.1604361

\section{Address the Uncontrolled Spread of Infections}

We are not achieving population "herd" immunity at current levels of vaccine coverage. It is reckless to assume we can open up society and remain shielded from the worst effects of the virus. Allowing further uncontrolled spread of the virus creates opportunities for further variants of concern to emerge, at least one of which will be vaccine resistant [3].

Priority must be given to expanding genetic sequencing to detect virus mutations, with internationally agreed standards and shared resources and support [3].

Continued social distancing measures and wearing of face masks is necessary irrespective of vaccination status [4]. Improving the effectiveness of contact tracing and financial support for self-isolation is needed [5].

Countries should critically review their policies with regard to mass gatherings, learning from previous experience of superspreading events [6] and evaluation of the experience of the Euros 2020.

EU institutions should agree a strong common European policy on border controls, harmonized and effectively implemented by each Member State [3].

\section{Recognise the Increasing Range of Clinical Presentations}

There is widespread under-ascertainment of cases of COVID-19 infection and a high frequency of asymptomatic infection [3]. Testing for COVID-19 needs be extended to a broader range of suspicious symptoms. The public needs to recognize the widening range of symptoms of COVID-19 and why they should be tested, even if their symptoms are mild [3]. 


\section{Recognise and Address the Widening Range of Syndromes and Clinical Consequences of "Long COVID", "Persistent COVID" and COVID Related Medical Conditions}

Health-care services must prepare to respond to COVID-19 associated medical conditions [3]. Enhanced surveillance is needed for COVID19 sequelae and COVID-associated medical conditions. There should be an international agreement on categories of long COVID manifestations and a surveillance system implemented [3].

\section{Rethink Inadequate Testing Tools and Strategies and Improve Public Understanding of the Limits of Tests}

The systematic replacement of PCR tests by rapid tests has increased the risk of false negatives making it difficult to control transmission. Governments need to see testing as part of the toolbox for reducing transmission, but recognise its limitations and convey accurate information the general public [3].

\section{Continue to Implement Mass Vaccination and Consistent Equitable Coverage of Their Population}

Countries must improve vaccination coverage rapidly. They must strengthen efforts to address vaccine hesitancy [7]. Continued vigilance in surveillance of vaccine efficacy is needed. Countries must ensure that vaccines are distributed equitably in their communities, and internationally [8].

\section{Address Unmet Health Care Needs}

Countries still need to address unrecognised, untreated or uncontrolled long-term conditions and conditions requiring surgery during the pandemic. Health services must take advantage where there is a decrease in COVID-19 cases requiring hospitalisation to address the backlog in regular care. Governments must resist relaxations which risk an increase in COVID-19 hospital bed-occupancy and prevent any recovery in routine and emergency care [2].

\section{Plan for Winter}

In addition to planning for COVID-19, countries must plan for a major flu outbreak this year. Flu was greatly suppressed during 2020, through high flu vaccination rates, social distancing and mask wearing. These will have impacted on transmission of any respiratory viruses, and are still needed in 2021 [9].

Enhanced Influenza, pneumococcal vaccine programmes and vitamin D supplementation also need to be implemented [2].

Countries should prepare for a cold winter [2], and for extreme and unpredictable weather events, like those happening with flash floods in Europe and with the extreme heat dome over the North Western Pacific region [10].

Efforts to stimulate economies by reducing societal COVID-19 restrictions will fail if the virus is not suppressed to very low levels [11]. Countries must protect the health and the social welfare of all their people $[2,3]$. Countries must protect their children's future; keeping schools open should be the priority $[12,13]$.

\section{Appreciate Their Global Responsibility to all Other Nations of the World}

We will not be free of the pandemic until we are all free of it [14]. It is grossly irresponsible for any country to abandon all public health and social protection measures. It is an action, not confined to their own borders. It will have wide-ranging impact across the globe and weaken global efforts to suppress the virus [15]. The possibility of perpetual COVID remains real [16].

\section{Earn the Trust of Your People, Govern by Informed Consent and Support Communities and Individuals}

Communication strategies must change from the message of protecting the health system capacity and the lives of older individuals, to protecting young individual's health over the long term due to the risk of long COVID-19 sequelae [3]. Some of the new SARS-COV2 variants will have an impact on the effectiveness of vaccines and put in jeopardy the huge vaccination efforts that have been made. This will have consequences for public trust and vaccine confidence.

Communication of the medium-term risks is essential for people to understand and give their support preventive efforts. Our governments and public health experts must earn the trust of the public we serve, and consent to the measures which must be implemented [2,3].

Our messages must be clear, consistent and unequivocal. We can be optimistic, but we cannot be complacent in our efforts towards the end of this pandemic.

\section{AUTHOR CONTRIBUTIONS}

VRP contributed the preliminary draft developed by JR, VP, IS, and JM published by ASPHER as [3]. JR, HL, and JM developed third wave and winter planning aspects of the paper. All authors contributed to conclusion and final manuscript. Paper endorsed by ASPHER COVID task force, July 22nd, 2021. Task force membership can be found here: https://www.aspher.org/covid19-task-force.html.

\section{CONFLICT OF INTEREST}

The authors declare that the research was conducted in the absence of any commercial or financial relationships that could be construed as a potential conflict of interest.

\section{SOCIETY NOTE}

ASPHER is responsible and liable for the content. The statement was approved by an Editor-in-Chief but not externally peer reviewed. 


\section{REFERENCES}

1. Chatarjupalli, P., Andelic, P., Ghoke, L., Reintjes, R., Czbanovska, K., and Middleton, J. ASPHER COVID-19 Situation Reporting Week of July $5^{\text {th }} 2021$. 2021, ASPHER, Brussels, Belgium, available at: https://www.aspher.org/ download/792/aspher_covid-19_situation_reporting_05_07_21.pdf, (accessed July 16th 2021).

2. Middleton, J., Lopes, H., Michelson, K., and Reid, J. Planning for a Second Wave Pandemic of COVID-19 and Planning for winter. Int J Public Health 65, (2020), available at: https://link.springer.com/article/10.1007/s00038-02001455-7. doi:10.1007/s00038-020-01455-7

3. Peixoto, V. R., Reid, J., Prikazsky, V., Siepmann, I., and Middleton, J. COVID-19 Is at Crossroads in Europe in Summer 2021: Risks of the Third Waveand the Need to Anticipate Scenarios, Considering Pitfalls (2021). ASPHER, Brussels, Belgium, available at: https://www.aspher.org/download/776/aspher-covid-report_ europe-at-a-crossroads.pdf, (accessed July 16th 2021).

4. Sesa, G., and Martin-Moreno, J. John Middleton ASPHER Statement on the Abolition of Mandatory Prevention Measures in the US for Fully Vaccinated Individuals 26 May 2021. available at: https://www.aspher.org/news,44.html https://www.aspher.org/download/726/aspher_statement_on_abolition_of_ prevention_measures.pdf, 2021, ASPHER, Brussels, Belgium.

5. Smith, L. E., Potts, H. W. W., Amlôt, R., Fear, N. T., Michie, S., and Rubin, G. J. Adherence to the Test, Trace, and Isolate System in the UK: Results from 37 Nationally Representative Surveys. BMJ (2021) 372:n608. doi:10.1136/bmj.n608

6. Philip, R. Tracking the Superspreader Events Driving the COVID-19 Pandemic. Global Investigative Journalism Network, Amsterdam, Netherland, 2020. available at: https:/gijn.org/2020/10/26/tracking-the-superspreader-eventsdriving-the-covid-19-pandemic/, (accessed July 16th 2021).

7. Sesa, G., Wong, B., Czbanovska, K., Reid, J., Davidovitch, N., Martin-Moreno, J. M., et al. Covid-19 Vaccine Passports and Vaccine Hesitancy: freedom or Control? BMJ London, UK, (2021). available at: https://blogs.bmj.com/bmj/2021/03/30/ covid-19-vaccine-passports-and-vaccine-hesitancy-freedom-or-control/.

8. Wong, B. L. H., Green, M. S., Reid, J. R., Martin-Moreno, J. M., Davidovitch, N., Chambaud, L., et al. Oward 'Vaccine Internationalism': The Need for an Equitable and Coordinated Global Vaccination Approach to Effectively Combat COVID-19. Int J Public Health (2021). doi:10.3389/ijph.2021.1604077

9. Academy of Medical Sciences, Uk. Winter Viruses and Covid-19 Could Push the NHs to Breaking point. London, UK: Academy of Medical Sciences (2021). available at: https://acmedsci.ac.uk/more/news/winter-viruses-and-covid-19could-push-nhs-to-breaking-point-warns-new-report, (accessed July 16th 2021).
10. Han, E., Tan, M. M. J., Turk, E., Sridar, D., Leung, G., and Shibuya, K. Lessons Learnt from Easing COVID-19 Restrictions: an Analysis of Countries and Regions in Asia Pacific and Europe. Lancet, 396, 2021, available at: https://www. thelancet.com/pdfs/journals/lancet/PIIS0140-6736(20)32007-9.pdf, (accessed July 18th 2021).

11. Puiu, T. Devastating Floods in Western Europe Exceed Even Worst Climate Change Predictions: The New Climate normal Is Frightening. ZME Science, București, Romania, 2021, available at: https://www.zmescience.com/ecology/ climate/western-europe-floods-053252/.

12. Deguen, S., and Lopes, H. ASPHER Second Statement on "Children and COVID: Closing or Keep Opening the Schools: The Consequences" UNICEF, New York, NY, USA, 2021. available at: https://www.aspher.org/download/766/ aspher_statement-children_and_covid-closing_or_keep_opening_the_schools. pdf, (accessed July 17th 2021).

13. Kluge, H., Khan, A., and Zhan, T. Use the Summer to Prepare for a Safe Return to School: Children and Youth Cannot Risk Having Another Year of Disrupted Learning. Etterbeek, Belgium: UNICEF, (2021). available at: https:// euobserver.com/opinion/152389.

14. World Health Organisation. A Global Pandemic Requires a World Effort to End it - None of Us Will Be Safe until Everyone Is Safe: Access to Vaccines, Tests and Treatments for Everyone Who Needs Them Is the Only Way Out (2020). Geneva, Switzerland: WHO. available at: https://www.who.int/ news-room/commentaries/detail/a-global-pandemic-requires-a-world-effort-toend-it-none-of-us-will-be-safe-until-everyone-is-safe (accesssed July 16th 2021).

15. Gurdasani, D., Drury, J., Greenhalgh, T., Griffin, S., Haque, Z., Hyde, Z., et al. Mass Infection Is Not an Option: We Must Do More to Protect Our Young. 398, Lancet 2021. available at: https://www.thelancet.com/journals/lancet/ article/PIIS0140-6736(21)01589-0/fulltext, (accessed July 16th 2021). doi:10.1016/S0140-6736(21)01589-0

16. Middleton, J. Is England's Exit Plan from Lockdown a Road to Nowhere? BMJ Opinion February 25th 2021 (London: British Medical Journal). available at: https://blogs.bmj.com/bmj/2021/02/25/is-englands-exit-plan-from-lockdowna-road-to-nowhere/ 2021, (accessed July 16th 2021).

Copyright (C) 2021 Peixoto, Reid, Lopes, Prikazsky, Siepmann, Martin-Moreno and Middleton. This is an open-access article distributed under the terms of the Creative Commons Attribution License (CC BY). The use, distribution or reproduction in other forums is permitted, provided the original author(s) and the copyright owner(s) are credited and that the original publication in this journal is cited, in accordance with accepted academic practice. No use, distribution or reproduction is permitted which does not comply with these terms. 